\title{
$\angle$ Research Square \\ An Online Survey to Assess Parents' Preferences for Learning About Child Health Research
}

\section{Lisa Knisley}

Faculty of Nursing, University of Alberta, Edmonton, Canada https://orcid.org/0000-0003-1056-3790

Anne Le

Faculty of Nursing, University of Alberta, Edmonton, Canada

Shannon D Scott ( $\sim$ shannon.scott@ualberta.ca)

Faculty of Nursing, University of Alberta, Edmonton, Canada https://orcid.org/0000-0002-2251-3742

\section{Research article}

Keywords: pediatrics, child health, patient engagement, communication, research, acute care, emergency

Posted Date: October 19th, 2020

DOl: https://doi.org/10.21203/rs.3.rs-92280/v1

License: (1) This work is licensed under a Creative Commons Attribution 4.0 International License.

Read Full License

Version of Record: A version of this preprint was published at Nursing Open on August 12th, 2021. See the published version at https://doi.org/10.1002/nop2.1027. 


\section{Abstract}

Background: Child health research is crucial to finding safe and effective treatments for children. However, child health research can be challenging in that it can require significant resources. Additionally, parents may need to make the decision to participate in a study during a stressful situation, such as an emergency department visit. Although innovative study design and methodology are being used to try and address these challenges, a key component of conducting more efficient, relevant and successful child health research is finding better ways to engage and involve parents in the research process from study conception to dissemination of results.

Methods: We employed a cross-sectional, survey design to seek feedback from parents on 1) how they would like to learn about potential child health research studies that their child could participate in; 2) whether they would like to learn more about the research studies they are participating in; and 3) how they would like to receive information about studies they are participating in.

Results: The survey findings demonstrate that parents are interested in hearing about opportunities to participate in child health research, particularly during visits to their general practitioner/pediatrician or walk-in clinics. Most parents would like to receive updates on the progress, results, and researchers involved in studies their child has participated in. Parents would also like to be provided with support to participate in research studies (i.e., travel or child care).

Conclusion: This study is part of a larger initiative that is re-examining recruitment and retention methods to inform research teams in planning child health studies. In order to involve a wider range of parents and children in current and future studies, there must be strong engagement strategies in place, developed with parents, to effectively and respectively share research opportunities, progress and results, and demonstrate that their participation matters.

\section{Plain English Abstract}

Research is important to finding safe and helpful treatments for children. But, research with children can be difficult to organize because it usually needs many hospitals to recruit enough children to participate. Also, parents sometimes are asked to make the decision for their child to participate in research during a stressful time, like an emergency department visit. Researchers are looking at new ways to design and organize studies so they are easier to do. An important part of this is finding better ways to let parents know about new studies, how to take part, who the research team is, and what the study results are.

We asked parents to fill out an online survey on how they wanted to hear about research for their child. Most of the parents who completed the survey told us that they are interested in hearing about opportunities for their child to take part in research, particularly during visits to their family doctor/pediatrician or walk-in clinics. Most parents would like to get updates on the progress, results, and the researchers involved in the studies their child has participated in. Parents would also like to be given support to participate in research studies (i.e., travel or child care). These survey results can help research 
teams find better ways to share information about child health research with parents and hopefully make it easier for parents and their child to take part in a research study.

\section{Background}

Child health research is crucial to determining safe and effective treatments for children $(1,2)$. However, significant resources are needed to conduct the research; for instance, participation from multiple health centres are usually required in order to recruit enough participants in a timely manner. Participant recruitment challenges can also present when conducting research in acute care settings such as an emergency department. Patients tend to be there for a short time, may not live in the immediate area, there is usually no established relationship between the emergency clinician and potential research participants, and there are less opportunities for follow-up in comparison to a primary care centre or specialist clinic (3). Research in an emergency setting is also further complicated by the understandable, potential reluctance of a parent to hearing about a research study while their child is acutely ill or injured (4). The KidsCAN (5) Pediatric Emergency Research Canada (PERC) (6) Innovative Pediatric Clinical Trials (iPCT) initiative aims to address these challenges by using innovative methodology to design and conduct clinical trials in a children's emergency department (7). A key component to achieving this is finding better ways to engage and involve parents in the research process from study conception to dissemination of results, with the aim of conducting more efficient, relevant and successful child health research.

There is a major gap in the evidence base on effective recruitment strategies for research studies (8). In a recent research prioritization exercise, parents identified emergency department communication as a priority for pediatric emergency research and that community engagement in health services research should be a guiding principle for all pediatric emergency research (9). Parents are gatekeepers to their children's access to study information, and it is crucial to understand their communication preferences (10) in order to improve recruitment and retention strategies. This study sought from parents on: 1) how they would like to learn about potential child health research studies that their child might be eligible for; 2) whether they would like to learn more about the research studies they are participating in; and 3) how they would like to receive information about studies they are participating in. The results will inform the KidsCAN PERC iPCT initiative's re-examination of recruitment and retention strategies for pediatric emergency department research studies.

\section{Methods}

\section{Study setting}

The study was conducted at the University of Alberta and leveraged our partner organizations' existing parent/public advisory groups within Alberta and Manitoba. The study was approved by the University of Alberta research ethics board (\#Pro00081012) with survey completion serving as presumed consent. 


\section{Study Instrument}

An online survey was developed, guided by the Public and Patient Engagement Evaluation Tool (11). The survey consisted of 29 multiple choice research questions (5-point Likert scale) and 7 demographics questions and took approximately 5-10 minutes to complete. The questionnaire was only available in English.

The first page of the survey contained information about the study purpose. Participants were able to read through this page before deciding on whether to participate in the study. By clicking the "yes" button to the question "Do you agree to participate in this study?" and completing the survey, consent was implied. Participants could refuse to answer any questions, stop the survey at any time, or withdraw from the study prior to submitting the survey. Participants who did not submit their survey data by pressing the submit button were not included in the data analysis. Once submitted, the completed surveys were uploaded to a secure, Canadian server. At this point, data were anonymous, contained no identifying information and data withdrawal was no longer possible. All submitted surveys had a $100 \%$ completion rate. The completed surveys were anonymous.

\section{Study Participant Recruitment}

Participants needed to be a parent or guardian of a child and able to read English. The survey was distributed through our partner organizations' research or patient/public advisory group electronic mailing lists, which included the: (1) Alberta Strategy for Patient Orientated Research (SPOR) SUPPORT Unit Patient Engagement Panel, (2) University of Alberta - Edmonton Pediatric Parent Advisory Group, (3) George \& Fay Yee Centre for Healthcare Innovation Patient and Public Advisory Group, (4) Translating Emergency Knowledge for Kids - Winnipeg Parent Advisory Group, and (5) University of Alberta and University of Calgary Healthy Infants and Children Clinical Research Program (HICCUP) database. The circulated email included the full study information letter along with a link to the survey website.

\section{Study Design}

We employed a cross-sectional, survey design. An initial email, followed by a reminder email approximately two weeks later, was sent to 261 potential participants from the electronic mailing lists between April 12, 2018 and July 15, 2018. As surveys were completed, data were submitted to the SimpleSurveys (simplesurvey.com) secure servers. SimpleSurveys software is a secure, online platform that stores data on servers in Canada, employing firewalls and three physical layers of security. Once data collection was completed, data were transferred to the researchers for analysis and long term, secure storage, and subsequently deleted from the SimpleSurveys servers. Data were cleaned and analyzed using SPSS v.25. Descriptive frequencies were calculated for demographic data and survey questions.

\section{Results}

We received 77 responses out of a potential 261 participants (30\% response rate). Demographic data (Table 1) were obtained in order to understand the population sample that responded to our questionnaire. This information was self-reported, submitted anonymously and could not be traced back 
to any individual. The majority of participant were female (94.8\%), aged $31-40$ years $(51.9 \%)$ and married $(88.3 \%)$. The majority of participants had either a post-secondary $(28.6 \%)$ or graduate degree $(49.4 \%)$, a gross annual household income of over $\$ 100,000(29.9 \%)$ or over $\$ 150,000(37.7 \%)$, and either one child $(27.3 \%)$ or two children (48.1\%). Most parents $(77.9 \%)$ had a child that had participated in a research study, but only $28.6 \%$ had received results from that study. Parents also expressed the importance of providing the supports needed (e.g., travel, child care, etc.) to participate in a research study $(83.2 \%$ agreed or strongly agreed).

Parents were asked their preference for hearing about opportunities to participate in child health research studies. Respondents were interested in hearing about opportunities to participate in child health research (Table 2 ) with participants stating they strongly agreed $(70.1 \%)$ or agreed $(28.6 \%)$. Parents were most interested (i.e., stated they either strongly agreed or agreed) in hearing about these opportunities from their child's general practitioner/pediatric appointments (88.4\%), via their child's school newsletter (87.1\%), in an email from their child's healthcare provider (85.8\%), via a poster on a clinic waiting room bulletin board $(85.8 \%)$, or via a community centre newsletter $(84.5 \%)$. The use of social media to communicate about child health research had mixed responses with $20.8 \%$ of parents strongly agreeing to this form of communication and $20.8 \%$ disagreeing with its use. Radio and TV advertisements were not the preferred choices. Although most respondents either strongly agreed $(19.5 \%)$ or agreed $(37.7 \%)$ that they were interested in hearing about child health studies during an emergency department visit, $19.5 \%$ of respondents strongly disagreed with this approach. Interestingly, this was the highest percentage of strongly disagree responses for this category.

Parents were interested in receiving information about studies their child had participated in $(72.7 \%)$. Respondents agreed or strongly agreed that they would like to receive information about study results $(100 \%)$, progress $(79.3 \%)$ and the researchers involved (68.9\%). They preferred (i.e., agreed or strongly agreed) to receive this information via an email newsletter $(92.2 \%)$ or via an email with an online link to more information (90.9\%). Most parents did not prefer to get a mailed newsletter (36.4\%) and $28.6 \%$ of parents neither agreed nor disagreed with this approach. Most parents also did not prefer to receive study updates via Facebook (45.5\%), Instagram (61.1\%) or Twitter (63.7\%).

\section{Discussion}

Our findings demonstrate that parents would like information about child health studies they might be eligible for, and they would like to be updated on the research teams, progress and results of the study their child is participating in. These findings mirror results from other studies and reviews that have shown parents are interested in learning about the research teams (12) and want to be informed of research results $(13 ; 14)$. Despite this, most participants do not receive this information (15).

In our study, participants did not prefer to hear about new studies through a mailed pamphlet, but rather during a visit with their child's healthcare provider or through existing general practitioner (GP), school or community centre newsletters and bulletin boards, suggesting the importance of communicating efficiently through existing, trusted organizations. However, in a systematic review comparing participant 
recruitment methods for randomized control trials (RCT), how or when the information was presented or who presented the information did not influence trial recruitment, but rather the information provided (16). Recruitment strategies that increase potential participants' awareness about the health problem being studied and its impact on their health appeared to be more effective (16).

The Health Research Authority (17) in the United Kingdom has recognized that printed media may not always be the best format and recommends exploring the usefulness of other media that may be more appropriate (e.g., videos, cartoons, animations, infographics, audio) for communicating trial information. Studies have shown that receiving study information via multimedia can have several benefits over written information sheets, including enhancing the understanding of complex information (12), and providing information in appropriate depth based on patient preferences (18). Yet, these approaches may require reasonably good computer skills and reliable internet access.

Social media was not a preferred source for receiving study information by participants in our survey. However, participants were already engaged with the healthcare system through participation in previous research or part of a patient/public advisory group. While research on the effectiveness of social media recruitment is still in its infancy, studies have shown effectiveness in using social media with populations that are historically hard-to-reach (19), including LGBT young adults (20) and young cancer survivors (21).

In our study, more purposeful recruitment strategies such as emails from a child's healthcare provider did not generate more support than passively using posters. Participants had mixed responses on whether they wanted to be informed of new studies for their child during an emergency department visit, highlighting the complexity of trial recruitment within this setting and the need for more research in this area. Our findings suggest that parents are more interested in hearing about research studies in nonurgent care settings (e.g. pediatrician/GP, walk-in clinic visits), which could be venues to promote awareness of emergency department research (e.g., poster on a GP waiting room bulletin board) prior to an emergency department visit.

Interpersonal interactions and relationships between potential trial participants and recruiters can be particularly important when people find their children in urgent, unfamiliar and potentially life-threatening situations (16). In a systematic review of methods to improve recruitment to clinical trials, promising strategies included telephone reminders to non-responders, opt-out strategies, and the use of open trial designs (22). Yet, telephone reminders to recruit participants are not practical for research that is conducted during an unexpected visit to the emergency department. Further research is needed to explore the use of opt-out strategies and open trial designs within an emergency department setting and the feasibility of these strategies during the emergency care of a child.

Much uncertainty remains in the literature regarding evidence-informed recruitment strategies for pediatric trials. Recruitment challenges will persist without the evaluation of alternative approaches to recruitment (23). Further research is needed on parents' experiences and preferences for informed decision-making in stressful situations such as an emergency department visit, and the use of prior 
information and alternative formats for the consent process (24). Sully, Julios \& Nicholl (25) suggest more advanced statistical methods should be considered by researchers during trial planning and analysis. In order to maximize trial participation within an emergency department setting, the KidsCAN PERC iPCT initiative is incorporating a novel preference-informed complementary trial design that allows caregivers to choose which of two simultaneous trials they wish their child to participate in (7). A qualitative exploration of the reasons behind the caregiver's decision is also being planned (7).

Lack of information on study progress and results have been cited as a top barrier to success in clinical trials (26). Since 2014, it has been a regulatory requirement of the European clinical trials database (27) to provide clinical trial results to participants in a clear, comprehensive, concise, relevant and understandable format. This is not a regulatory requirement in North America, but there is increasing recognition that providing these summaries should be considered the ethical norm $(28,14)$. Previous research has suggested the use of printed summaries to share study results to meet participant preference and to provide a physical demonstration of appreciation for their participation (15). In our study, participants preferred electronic communication via email to receive these results, aligning with the increasing expectation and preference of people to have information available online (17).

\section{Conclusions}

Parents are interested in hearing about opportunities to participate in child health research, particularly during visits to their GP/pediatrician or walk-in clinics. Most parents would like to receive updates on the progress, results, and researchers involved in studies their child has participated in. Parents would also like to be provided with support to participate in research studies (i.e., travel or child care). Our study was an initial step in the KidsCAN PERC iPCT initiative's re-examination of recruitment and retention methods that can inform researchers in planning child health studies. In order to involve a wider range of parents and children in current and future studies, there must be strong communication strategies in place, developed with parents, to effectively and respectively share research opportunities, progress and results, and demonstrate that their participation matters.

\section{List Of Abbreviations}

HICCUP - Healthy Infants and Children Clinical Research Program

iPCT - Innovative Pediatric Clinical Trials

LGBT - Lesbian, Gay, Bisexual, Transgender

PERC - Pediatric Emergency Research Canada

SPOR - Strategy for Patient Orientated Research

\section{Declarations}


Ethics approval and consent to participate

The study was approved by the University of Alberta research ethics board (\#Pro00081012) with survey completion serving as presumed consent.

\section{Consent for publication}

Not applicable

\section{Availability of data and materials}

The datasets used and/or analysed during the current study are available from the corresponding author on reasonable request

\section{Competing interests}

The author(s) declare(s) that they have no competing interests.

\section{Funding}

This work was supported by the Canadian Institutes of Health Research - Strategy for Patient Orientated Research Innovative Clinical Trial Multi-Year Grant under grant [MYG-151207; 2018 - 2020]. S.S. holds a Canada Research Chair in Knowledge Translation in child health and is a Distinguished Researcher through the Stollery Science lab, Stollery Children's Hospital Foundation.

\section{Authors' contributions}

S.S. and L.K. contributed to the study design. A.L. contributed to data collection and analysis. All authors contributed to the interpretation of data. L.K. drafted the manuscript and S.S. and A.L. made substantive revisions to it.

\section{Acknowledgements}

We want to thank the Pediatric Emergency Research Canada (PERC) network of healthcare professionals and the KidsCAN Trials Network for their contribution and support to this project and pediatric clinical research in Canada.

\section{References}

(1) Klassen TP, Hartling L, Craig JC, Offringa M. Children are not just small adults: The urgent need for high-quality trial evidence in children. PLoS medicine 2008;5(8):1180 e172-1182.

(2) Modi N, Prof, Clark H, Prof, Wolfe I, MSc, Costello A, Prof, Budge H, PhD. A healthy nation: strengthening child health research in the UK. Lancet, The 2013;381(9860):73-87. 
(3) Cofield SS, Conwit R, Barsan W, Quinn J. Recruitment and Retention of Patients into Emergency Medicine Clinical Trials. Academic emergency medicine : official journal of the Society for Academic Emergency Medicine 2010 Oct;17(10):1104-1112.

(4) Chamberlain JM, Lillis K, Vance C, Brown KM, Fawumi O, Nichols S, et al. Perceived Challenges to Obtaining Informed Consent for a Time-sensitive Emergency Department Study of Pediatric Status Epilepticus: Results of Two Focus Groups. Academic Emergency Medicine 2009 Aug;16(8):763-770.

(5) KidsCAN Clinical Trials for Children. https://www.kidscantrials.ca

(6) Bialy L, Plint A, Zemek R, Johnson D, Klassen T, Osmond M, et al. Pediatric Emergency Research Canada: Origins and Evolution. Pediatric Emergency Care 2018 Feb;34(2):138-144.

(7) Kelly LE, Richer L, Ali S, Plint AC, Poonai N, Freedman SB, et al. Innovative approaches to investigatorinitiated, multicentre paediatric clinical trials in Canada. BMJ Open 2019 Jun;9(6):e029024.

(8) Bower P, Brueton V, Gamble C, Treweek S, Smith CT, Young B, et al. Interventions to improve recruitment and retention in clinical trials: a survey and workshop to assess current practice and future priorities. Trials 2014 Oct 16;15(1):399.

(9) Bialy L, Plint AC, Freedman SB, Johnson DW, Curran JA, Stang AS, et al. Pediatric Emergency Research Canada (PERC): Patient/Family-informed Research Priorities for Pediatric Emergency Medicine. Academic Emergency Medicine 2018 Dec;25(12):1365-1374.

(10) Coyne I. Accessing children as research participants: examining the role of gatekeepers. Child: Care, Health and Development 2010 Jul;36(4):452-454.

(11) Abelson J, \& the PPEET Research-Practice Collaborative. The Public and Patient Engagement Evaluation Tool Version 1.0. 2015 June. Retrieved from

https://healthsci.mcmaster.ca/ppe

(12) Martin-Kerry JM, Knapp P, Atkin K, Bower P, Watt I, Stones C, et al. Supporting children and young people when making decisions about joining clinical trials: qualitative study to inform multimedia website development. BMJ Open 2019 Jan;9(1):e023984.

(13) Shalowitz DI, Miller FG. Communicating the Results of Clinical Research to Participants: Attitudes, Practices, and Future Directions. PLoS medicine 2008 May 13;5(5):e91.

(14) Fernandez CV, Gao J, Strahlendorf C, Moghrabi A, Davis Pentz R, Barfield RC, et al. Providing Research Results to Participants: Attitudes and Needs of Adolescents and Parents of Children With Cancer. Journal of Clinical Oncology 2009 Feb 20,;27(6):878-883. 
(15) Hallinan ZP, Getz KA. Communicating trial results to study volunteers: what does the future hold? Clinical Investigation 2014 Sep;4(9):777-779.

(16) Caldwell PHY, Hamilton S, Tan A, Craig JC. Strategies for Increasing Recruitment to Randomised Controlled Trials: Systematic Review. PLoS medicine 2010 Nov 9;7(11):e1000368.

(17) Health Research Authority. Applying a proportionate approach to the process of seeking consent. HRA Guidance. National Health Service, 2017:31.

(18) Antoniou EE, Draper H, Reed K, Burls A, Southwood TR, Zeegers MP. An empirical study on the preferred size of the participant information sheet in research. Journal of Medical Ethics 2011 Sep;37(9):557-562.

(19) Gelinas L, Pierce R, Winkler S, Cohen IG, Lynch HF, Bierer BE. Using Social Media as a Research Recruitment Tool: Ethical Issues and Recommendations. The American Journal of Bioethics 2017 Mar $4, ; 17(3): 3-14$.

(20) Guillory J, Wiant KF, Farrelly M, Fiacco L, Alam I, Hoffman L, et al. Recruiting Hard-to-Reach Populations for Survey Research: Using Facebook and Instagram Advertisements and In-Person Intercept in LGBT Bars and Nightclubs to Recruit LGBT Young Adults. Journal of medical Internet research 2018 Jun 18;20(6):e197.

(21) Gorman JR, Roberts SC, Dominick SA, Malcarne VL, Dietz AC, Su HI. A Diversified Recruitment Approach Incorporating Social Media Leads to Research Participation Among Young Adult-Aged Female Cancer Survivors. Journal of Adolescent and Young Adult Oncology 2014 Jun 1,;3(2):59-65.

(22) Treweek S, Lockhart P, Pitkethly M, Cook JA, Kjeldstrøm M, Johansen M, et al. Methods to improve recruitment to randomised controlled trials: Cochrane systematic review and meta-analysis. BMJ Open 2013;3(2):e002360.

(23) Treweek S, Pitkethly M, Cook J, Fraser C, Mitchell E, Sullivan F, et al. Strategies to improve recruitment to randomised trials (Review). 2018.

(24) Jansen-van der Weide, Marijke C, Caldwell PHY, Young B, de Vries MC, Willems DL, van't Hoff W, et al. Clinical Trial Decisions in Difficult Circumstances: Parental Consent Under Time Pressure. Pediatrics 2015;136(4):e983-e992.

(25) Sully BGO, Julious SA, Nicholl J. A reinvestigation of recruitment to randomised, controlled, multicenter trials: a review of trials funded by two UK funding agencies. Trials 2013 Jun 9;14(1):166.

(26) Carroll, C., Tom, I., Helen, M., Jon, S. A clinical trials 'charter' to improve communication about, recruitment to and retention in Parkinson's clinical trials. Disorder 2016; 31(supp 2). 
(27) The European Parliament and the Council of the European Union. Regulation (EU) No 536/2014 of the European Parliament and of the Council of 16 April 2014 on clinical trials on medicinal products for human use, and repealing Directive 2001/20/EC. Official Journal of the European Union 2014 April 6,.

(28) Partridge AH, Winer EP. Informing Clinical Trial Participants About Study Results. JAMA 2002 Jul $17 ; 288(3): 363-365$.

\section{Appendices}

Table 1. Demographic Characteristics 


\begin{tabular}{|ll|}
\hline Characteristic & $\mathbf{n}(\%)$ \\
Fex & \\
Male & $73(94.8)$ \\
Age & $4(5.2)$ \\
$20-30$ years & \\
$31-40$ years & $8(10.4)$ \\
$41-50$ years & $40(51.9)$ \\
51 years and older & $23(29.9)$ \\
\hline Marital Status & $6(7.8)$ \\
Married & \\
Single & $68(88.3)$ \\
\hline Education & $9(11.7)$ \\
\hline High school diploma & \\
Some post-secondary & $1(1.3)$ \\
Post-secondary certificate/diploma & $14(18.2)$ \\
Post-secondary degree & $22(28.6)$ \\
Graduate degree & $38(49.4)$ \\
\hline Gross annual household Income & \\
Less than \$25,000 & $3(3.9)$ \\
\$25,000-\$74,000 & $7(9.1)$ \\
\$75,000-\$99,000 & $12(15.6)$ \\
\hline \$100,000-\$149,000 & $23(29.9)$ \\
\hline Number of Children in the Family & \\
\hline
\end{tabular}


Table 2. Parents' Information Preferences

\begin{tabular}{|c|c|c|c|c|c|}
\hline & $\begin{array}{l}\text { Strongly } \\
\text { Agree }\end{array}$ & Agree & $\begin{array}{l}\text { Neither } \\
\text { Agree nor } \\
\text { Disagree }\end{array}$ & Disagree & $\begin{array}{l}\text { Strongly } \\
\text { Disagre€ }\end{array}$ \\
\hline $\begin{array}{l}\text { I am interested in hearing about } \\
\text { opportunities to participate in child health } \\
\text { research studies: }\end{array}$ & $\begin{array}{l}54 \\
(70.1)\end{array}$ & $\begin{array}{l}22 \\
(28.6)\end{array}$ & $1(1.3)$ & $0(0.0)$ & $0(0.0)$ \\
\hline $\begin{array}{l}\text { During my child's pediatrician/GP } \\
\text { appointment }\end{array}$ & $\begin{array}{l}36 \\
(46.8)\end{array}$ & $\begin{array}{l}32 \\
(41.6)\end{array}$ & $6(7.8)$ & $2(2.6)$ & $1(1.3)$ \\
\hline $\begin{array}{l}\text { During a visit to the emergency } \\
\text { department }\end{array}$ & $\begin{array}{l}15 \\
(19.5)\end{array}$ & $\begin{array}{l}29 \\
(37.7)\end{array}$ & $13(16.9)$ & $\begin{array}{l}14 \\
(18.2)\end{array}$ & $\begin{array}{l}15 \\
(19.5)\end{array}$ \\
\hline - $\quad$ During a walk-in clinic visit & $\begin{array}{l}21 \\
(27.3)\end{array}$ & $\begin{array}{l}35 \\
(45.5)\end{array}$ & $12(15.6)$ & $8(10.4)$ & $1(1.3)$ \\
\hline . In a community centre newsletter & $\begin{array}{l}36 \\
(46.8)\end{array}$ & $\begin{array}{l}29 \\
(37.7)\end{array}$ & $9(11.7)$ & $3(3.9)$ & $0(0.0)$ \\
\hline . In my child's school newsletter & $\begin{array}{l}34 \\
(44.2)\end{array}$ & $\begin{array}{l}33 \\
(42.9)\end{array}$ & $5(6.5)$ & $5(6.5)$ & $0(0.0)$ \\
\hline $\begin{array}{l}\text { In an email from my child's health } \\
\text { care provider }\end{array}$ & $\begin{array}{l}35 \\
(45.5)\end{array}$ & $\begin{array}{l}31 \\
(40.3)\end{array}$ & $8(10.4)$ & $1(1.3)$ & $2(2.6)$ \\
\hline $\begin{array}{l}\text { In a poster on a school or } \\
\text { community centre bulletin board }\end{array}$ & $\begin{array}{l}28 \\
(36.4)\end{array}$ & $\begin{array}{l}25 \\
(32.5)\end{array}$ & $15(19.5)$ & $8(10.4)$ & $1(1.3)$ \\
\hline $\begin{array}{l}\text { In a poster on a clinic waiting room } \\
\text { bulletin board }\end{array}$ & $\begin{array}{l}33 \\
(42.9)\end{array}$ & $\begin{array}{l}33 \\
(42.9)\end{array}$ & $7(9.1)$ & $3(3.9)$ & $1(1.3)$ \\
\hline $\begin{array}{l}\text { In advertisements on Facebook and } \\
\text { other social media }\end{array}$ & $\begin{array}{l}16 \\
(20.8)\end{array}$ & $\begin{array}{l}24 \\
(31.2)\end{array}$ & $16(20.8)$ & $\begin{array}{l}16 \\
(20.8)\end{array}$ & $5(6.5)$ \\
\hline . In a radio advertisement & $9(11.7)$ & $\begin{array}{l}14 \\
(18.2)\end{array}$ & $27(35.1)$ & $\begin{array}{l}19 \\
(24.7)\end{array}$ & $8(10.4)$ \\
\hline . $\quad$ In a TV advertisement & $9(11.7)$ & $\begin{array}{l}13 \\
(16.9)\end{array}$ & $25(32.5)$ & $\begin{array}{l}19 \\
(24.7)\end{array}$ & $\begin{array}{l}11 \\
(14.3)\end{array}$ \\
\hline . $\quad$ From a pamphlet mailed to me & $\begin{array}{l}20 \\
(26.0)\end{array}$ & $\begin{array}{l}27 \\
(35.1)\end{array}$ & $7(9.1)$ & $\begin{array}{l}15 \\
(19.5)\end{array}$ & $8(10.4)$ \\
\hline
\end{tabular}

Table 3: Parents' Information Needs 


\begin{tabular}{|c|c|c|c|c|c|}
\hline & $\begin{array}{l}\text { Strongly } \\
\text { Agree }\end{array}$ & Agree & $\begin{array}{l}\text { Neither } \\
\text { Agree nor } \\
\text { Disagree }\end{array}$ & Disagree & $\begin{array}{l}\text { Strongly } \\
\text { Disagree }\end{array}$ \\
\hline $\begin{array}{l}\text { I would like to receive information } \\
\text { about studies my child has participated } \\
\text { in }\end{array}$ & $\begin{array}{l}56 \\
(72.7)\end{array}$ & $\begin{array}{l}18 \\
(23.4)\end{array}$ & $3(3.9)$ & $0(0.0)$ & $0(0.0)$ \\
\hline \multicolumn{6}{|l|}{$\begin{array}{l}\text { I would like to receive information } \\
\text { about: }\end{array}$} \\
\hline . $\quad$ Progress & $\begin{array}{l}38 \\
(49.4)\end{array}$ & $\begin{array}{l}23 \\
(29.9)\end{array}$ & $7(9.1)$ & $8(10.4)$ & $1(1.3)$ \\
\hline - $\quad$ Results & $\begin{array}{l}62 \\
(80.5)\end{array}$ & $\begin{array}{l}15 \\
(19.5)\end{array}$ & $0(0.0)$ & $0(0.0)$ & $0(0.0)$ \\
\hline . $\quad$ Researchers involved & $\begin{array}{l}27 \\
(35.1)\end{array}$ & $\begin{array}{l}26 \\
(33.8)\end{array}$ & $21(27.3)$ & $3(3.9)$ & $0(0.0)$ \\
\hline \multicolumn{6}{|l|}{ I would like to receive this information: } \\
\hline . $\quad$ In an email newsletter & $\begin{array}{l}50 \\
(64.9)\end{array}$ & $\begin{array}{l}21 \\
(27.3)\end{array}$ & $6(7.8)$ & $0(0.0)$ & $0(0.0)$ \\
\hline . In a newsletter mailed to me & $\begin{array}{l}12 \\
(15.6)\end{array}$ & $\begin{array}{l}15 \\
(19.5)\end{array}$ & $22(28.6)$ & $\begin{array}{l}20 \\
(26.0)\end{array}$ & $8(10.4)$ \\
\hline $\begin{array}{l}\text { In an email that includes a link to } \\
\text { online information }\end{array}$ & $\begin{array}{l}41 \\
(53.2)\end{array}$ & $\begin{array}{l}29 \\
(37.7)\end{array}$ & $3(3.9)$ & $3(3.9)$ & $1(1.3)$ \\
\hline $\begin{array}{l}\text { In a text that includes a link to } \\
\text { online information }\end{array}$ & $\begin{array}{l}15 \\
(19.5)\end{array}$ & $\begin{array}{l}21 \\
(27.3)\end{array}$ & $14(18.2)$ & $\begin{array}{l}21 \\
(27.3)\end{array}$ & $6(7.8)$ \\
\hline . Through a Facebook page & $6(7.8)$ & $\begin{array}{l}14 \\
(18.2)\end{array}$ & $21(27.3)$ & $\begin{array}{l}21 \\
(27.3)\end{array}$ & $\begin{array}{l}14 \\
(18.2)\end{array}$ \\
\hline Through Instagram updates & $2(2.6)$ & $\begin{array}{l}5 \\
(6.5)\end{array}$ & $23(29.9)$ & $\begin{array}{l}20 \\
(26.0)\end{array}$ & $\begin{array}{l}27 \\
(35.1)\end{array}$ \\
\hline . $\quad$ From Twitter updates & $2(2.6)$ & $\begin{array}{l}4 \\
(5.2)\end{array}$ & $22(28.6)$ & $\begin{array}{l}24 \\
(31.2)\end{array}$ & $\begin{array}{l}25 \\
(32.5)\end{array}$ \\
\hline
\end{tabular}

